\title{
La tutela laboral de los derechos fundamen- tales del trabajador. Una asignatura pendiente en tiempos de reforma
}

\section{The labor guardianship of worker's fundamental rights: A pending subject in times of reform}

\section{ELMER ARCE*}

Resumen: El artículo tiene como punto de partida la penetración del Derecho Constitucional en las relaciones de trabajo impulsada principalmente por el Tribunal Constitucional, el cual, con sus reiteradas sentencias, ha precisado el contenido normativo de los derechos constitucionales de los trabajadores. A partir de ello, se sostiene que en materia de protección de los derechos fundamentales nos encontramos en medio de una vía ordinaria insuficiente y otra vía extraordinaria, la del amparo, también incapaz de asumir la protección adecuada del trabajador. El artículo analiza las particularidades que debe tener una demanda de violación de derechos fundamentales y que la diferencian de cualquier otra en sede laboral para recoger características como: celeridad acentuada, prioridad e impedir la improcedencia in limine. Finalmente, el texto concluye lamentando que la Nueva Ley Procesal del Trabajo no haya creado un proceso ad hoc para la protección de derechos fundamentales y que, por el contrario, se haya optado por un sistema disperso y caótico para la protección de los mismos.

Palabras clave: derechos fundamentales - tutela laboral - proceso laboral acción de amparo - Nueva Ley Procesal del Trabajo

Summary: The articlestarts with the penetration of Constitutional Law in labor relations mainly promoted by the Constitutional Court, which with its repeated statements have specified the normative content of workers' constitutional rights. From this, it maintains that in protection matters of fundamental rights we are in the middle of an insufficientordinary route and another extraordinary route, legal protection, also unable to assume adequate protection of workers. The article analyzes particularities that should have a claim of violation of the fundamental rights of any other in alabor site to pick up characteristics such as: accentuated swiftness, priority and preventing inadmissibility "in limine". Finally, the text concludes regretting that New Procedural Labor Lawhasn't created an ad hoc process for the protection of fundamental rights and that, on the contrary, it has opted for a disperse and chaotic system to protect them.

Keywords: fundamental rights - labor guardianship - labor process - appeal for legal protection - new procedural labor law

* Profesor de Derecho Laboral de la Pontificia Universidad Católica del Perú y doctor en Derecho por la Universidad de Cádiz, España. 
CONTENIDO: I. EL PORQUÉ DE UN PROCEDIMIENTO ESPECIAL DE DERECHOS

FUNDAMENTALES.- II.OTRAS CARACTERÍSTICAS DE UN PROCESO ESPECIAL.III.LAS LESIONES DE DERECHOS FUNDAMENTALES EN EL MARCO DE LA LEGISLACIÓN LABORAL ACTUAL.- IV.LOS PROCESOS ORDINARIOS LABORALES EN LA NUEVA LEY PROCESAL DEL TRABAJO.- V. COMPETENCIA DEL PROCESO ABREVIADO LABORAL EN MATERIA DE LESIONES DE DERECHOS FUNDAMENTALES.- V.1. LAS PRETENSIONES RELATIVAS A LA VULNERACIÓN DE LA LIBERTAD SINDICAL.- V.2. DE LA REPOSICIÓN CUANDO ESTA SE PLANTEE COMO PRETENSIÓN PRINCIPAL ÚNICA.- V.3. AFECTACIONES AL DERECHO DE REMUNERACIÓN CUANDO EL MONTO DE LA PRESTACIÓN SEA INFERIOR A 50 UNIDADES DE REFERENCIA PROCESAL (URP).- VI. COMPETENCIA DEL PROCESO ORDINARIO LABORAL EN MATERIA DE LESIONES DE DERECHOS FUNDAMENTALES.- VI.1. LOS ACTOS DE DISCRIMINACIÓN EN EL ACCESO, EJECUCIÓN Y EXTINCIÓN DE LA RELACIÓN DETRABAJO.- VI.2. EL CESE DE LOS ACTOS DE HOSTILIDAD DEL EMPLEADOR.- VII. EN ESTAS CIRCUNSTANCIAS, ¿ES IMPROCEDENTE LA ACCIÓN DE AMPARO?

Para nadie es un secreto que hoy día la empresa ya no es una zona franca irrespetuosa de la ciudadanía del trabajador y segregada de la sociedad civil $^{1}$. Los intereses del trabajador dentro de la empresa se han visto reforzados por el reconocimiento de sus derechos constitucionales, lo cual supone también el correlativo retroceso del poder de dirección empresarial.

Históricamente, el fenómeno más antiguo y consolidado es el de constitucionalización de los derechos laborales, cuyos titulares solo pueden ser trabajadores. Este es el caso, de los derechos colectivos o de la jornada máxima de trabajo. Sin embargo, hay un fenómeno más reciente denominado «laboralización de los derechos constitucionales», donde el trabajador, al entrar en la empresa, no pierde sus derechos como ciudadano. La doctrina también los ha denominado «inespecíficos» ${ }^{2}$. La laboralización de los derechos constitucionales pretende explicar cómo un derecho constitucional se modula una vez que ingresa a la relación laboral. Por ejemplo, el derecho a la libertad de expresión es un derecho de la persona también predicable en el seno de una relación laboral, no obstante admitirá ciertas restricciones propias del contexto empresarial y de la relación de subordinación.

Quizá el mayor exponente de esta suerte de penetración del Derecho Constitucional en las relaciones de trabajo ha sido el Tribunal Constitucional (TC), el cual con sus reiteradas sentencias ha precisado

1 Pedrajas moreno, Abdón. Despido y derechos fundamentales. Madrid: Trotta, 1992, p. 23.

2 Así los define Palomeque, «otros derechos de carácter general y, por ello, no específicamente laborales pueden ser ejercitados, sin embargo, por los sujetos de las relaciones de trabajo (los trabajadores, en particular) en el ámbito de las mismas, por lo que en tal caso adquieren un contenido o dimensiones laborales sobrevenidos» (PALOMEQUE LÓPEZ, Manuel Carlos. «Los derechos laborales en la Constitución Española». En Cuadernos y Debates. Madrid: Centro de Estudios Constitucionales, 1991, p. 31. 
el contenido normativo de los derechos constitucionales de los trabajadores. Paradigmáticas han sido sobre todo sus sentencias sobre el despido sin causa, por considerar que estos actos extintivos violan el derecho al trabajo (artículo 22 de la Constitución) ${ }^{3}$.

A pesar de que este proceso de sedimentación de los derechos fundamentales como límite al poder empresarial es, desde nuestra perspectiva, irreversible, consideramos que el juez laboral es el llamado a continuar la labor iniciada por el TC. Frente a la concepción residual de la acción de amparo que preside el Código Procesal Constitucional, las violaciones de derechos constitucionales de los trabajadores difícilmente llegarán hasta el TC. Urge, por tanto, desarrollar el ordenamiento jurídico procesal con el fin de dotar al juez ordinario laboral de los elementos necesarios para abordar la difícil misión de tutelar los derechos fundamentales de los trabajadores. Lejos de criticar al TC para que siga cubriendo el déficit de protección de la legislación laboral, creo que es hora de crear un procedimiento laboral ad hoc donde se ventile cualquier afectación de derechos constitucionales al trabajador.

En esta línea, la Nueva Ley Procesal del Trabajo (ley 29497) ha desperdiciado la gran oportunidad de crear un procedimiento especial de tutela de derechos fundamentales, como lo tiene Chile o España, que permita a los jueces laborales asumir su función sin necesitar de la venerable ayuda del TC.

\section{ELPORQUÉ DE UNA PROCEDIMIENTO ESPECIAL DE DERECHOS FUNDAMENTALES}

Para nadie es un secreto que las relaciones laborales tienen un alto índice de lesión de los derechos fundamentales del trabajador. Y ello, porque el poder de dirección cuenta con una fuerte presunción de legitimidad. De esta manera, si el trabajador alega una violación de un derecho constitucional, tendrá que presentar pruebas en contra de dicha presunción de legitimidad, lo cual resulta muy complicado, ya que un $99 \%$ de estas violaciones son encubiertas tras actos de aparente legalidad.

Creo que son dos los rasgos especiales que diferencian a una demanda de violación de derechos fundamentales de cualquier otra en sede laboral. El primer rasgo es la dificultad probatoria que tiene el trabajador en estos casos. Es por eso que en la mayoría de estos procesos, como sucede con la

3 Ver la sentencia recaída en el expediente 1124-2001-AA/TC (demanda de amparo presentada por el Sindicato de Telefónica del Perú); la sentencia recaída en el expediente 976-2001-AA/TC (demanda de amparo presentada por Eusebio Llanos Huasco); y, finalmente, la recaída en el expediente 206-2005-AA/TC (demanda de amparo presentada por César Baylón Flores). 
acción de amparo, se introducen mecanismos de facilitación probatoria que relajan los márgenes de certeza de la prueba ${ }^{4}$.

De otro lado, el segundo rasgo es el mecanismo reparador del que gozan los procedimientos especiales de tutela de derechos fundamentales. Como sucede con la acción de amparo, de lo que se trata es de «reponer las cosas al estado anterior de la violación del derecho fundamental». En otros procesos laborales se puede, como en los casos del mismo despido sin trascendencia constitucional o el cese de hostilidad, declarar ilícito el acto empresarial, pero no se declara la nulidad del acto. Este es el caso del despido arbitrario en el que se recibe el pago de una indemnización sin declararse la nulidad del despido 5 .

En la vía ordinaria laboral solo conocemos un caso de tutela especial, el cual es la regulación del despido nulo. Aquí el juez laboral puede declarar el despido como nulo y en el devenir del procedimiento otorgar facilidades probatorias. Sin embargo, su gran inconveniente está en su limitado ámbito de operatividad. A saber, solo se aplica a las causales a las que se refiere el artículo 29 de la Ley de Productividad y Competitividad Laboral (LPCL), así como a un acto concreto (despido), dejando de lado a la contratación y a la ejecución del contrato de trabajo.

\section{OTRAS CARCTERÍSTICAS DE UN PROCESO ESPECIAL} Junto a los mecanismos de facilitación probatoria y a los mecanismos restitutorios de reparación, la legislación comparada introduce otros instrumentos que confirman la naturaleza especial y urgente de la tutela de los derechos fundamentales. Vamos a enumerarlos a continuación.

1. Celeridad acentuada.- Se requiere una tramitación rápida. Sobre todo, esta clase de procesos debe acortar los plazos normales, ya que el bien jurídico protegido así lo aconseja.

2. Prioridad.-La naturaleza especial de los derechos fundamentales exige que las demandas que invocan su tutela deben ser tramitadas antes que otro tipo de procesos. Si se mira bien, este requerimiento no ha sido contemplado en nuestra legislación ni siquiera en el caso del despido nulo. Por el contrario, la acción de amparo sí tiene prioridad en su tramitación.

3. Impedir la improcedencia in limine.- Con ello se busca que la demanda no sea rechazada de plano por puras razones formales.

4 MANEIRO VÁzQuez, Yolanda. La tutela de los derechos fundamentales y libertades públicas por los tribunales laborales. La Coruña: Netbiblio, 2007, pp. 160 y ss.

5 A propósito del restablecimiento del derecho fundamental laboral violado, ver BAZ TEJEDOR, José Antonio. La tutela judicial de los derechos fundamentales en el proceso de trabajo, Valladolid: Lex Nova, pp. 226 y ss. 
El juez debe entrar al tema de fondo y relajar los controles de improcedencia razonablemente ${ }^{6}$.

4. Medidas cautelares eficaces.- Las medidas destinadas a garantizar la eficacia de la pretensión al final del proceso deben ser armas accesibles para cualquier juez laboral que se enfrenta a posibles afectaciones de derechos fundamentales. Las medidas cautelares deben estar dirigidas a reponer preventivamente las cosas al estado anterior a la violación del derecho violado. En este tema hay una mejora sustancial en la redacción de la Nueva Ley Procesal del Trabajo (aun cuando se focaliza predominantemente en el despido), ya que la ley 26636 era bastante lacónica a este respecto?

\section{LAS LESIONES DE DERECHOS FUNDAMENTALES EN EL MARCO DE LA LEGISLACIÓN LABORAL ACTUAL}

El campo de lo excluido del despido nulo es enorme. Lo más contradictorio es que cualquier violación de un derecho constitucional debe ser reconducida a una vía procesal ordinaria pensada para casos donde no existe afectación constitucional. Es evidente que las vías ordinarias no están preparadas para proteger este tipo de derechos.

Si el ámbito de operatividad del despido nulo está restringido solo a la libertad sindical, tutela judicial efectiva y prohibición de discriminación, ien qué vía procesal se protegerán los demás derechos fundamentales que podrían ser violados por el despido? Cuando nos referimos a los «demás» derechos fundamentales, lo hacemos pensando en la libertad de expresión, el derecho al trabajo, la intimidad, la libertad religiosa, etcétera. El despido arbitrario no podría asumir la defensa, ya que la reparación que ofrece es el simple pago de una indemnización. La respuesta más fácil podría ser la vía del amparo, ya que no existe otra vía procesal ordinaria igualmente eficiente, sin embargo, volvemos a tropezarnos con el problema de que el amparo no tiene etapa probatoria. El TC, en la sentencia recaída sobre el expediente 206-2005-PA/ TC, caso Baylón Flores, ha sido rotundo al afirmar que los amparos son improcedentes cuando se tenga que efectuar en el proceso una actividad probatoria. De esta manera, el trabajador sin amparo y con una vía ordinaria insuficiente se halla huérfano de protección de sus derechos fundamentales ${ }^{8}$.

6 Ver Baylos Grau, Antonio, Jesús Cruz Villalón \& María Fernanda Fernández lópez. Instituciones de Derecho Procesal Laboral. Madrid: Trotta, 1995, pp. 208-209.

7 Para un comentario sobre este tema, ver el reciente libro de MENDOZA LEGOAS, Luis. Las medidas cautelares laborales. Lima: ARA Editores, pp. 220 y ss.

8 Caso típico de lo que se dice es el del despido fraudulento que es excluido del amparo por el TC porque requiere desplegar una actividad probatoria. Obviamente, tampoco el despido arbitrario

LA TUTELA

LABORAL DE LOS

DERECHOS

FUNDAMENTALES

DEL TRABAJADOR.

UNA ASIGNATURA

PENDIENTE EN

TIEMPOS DE

REFORMA

THE LABOR

GUARDIANSHIP

OF WORKER'S

FUNDAMENTAL

RIGHTS:

A PENDING

SUBJECT IN TIMES

OF REFORM 
Creo que las lesiones de derechos fundamentales en la contratación y durante la ejecución del contrato tampoco cuentan con vías procesales adecuadas. Veamos cada uno de estos supuestos: en primer lugar, en la contratación no tenemos mecanismos procesales de protección. Es verdad que la ley 27270, ley contra actos de discriminación, viene a prohibir la discriminación en las ofertas de empleo o en el acceso a centros de formación educativa, no obstante, la reparación es meramente resarcitoria (artículo 3), pues se impone solo el pago de una indemnización al afectado. Al menos, en el acceso a centros de formación educativa se puede sancionar con la reposición de las cosas al estado anterior de la violación. Salvo este caso puntual, no existe protección de otros derechos al momento del acceso a una relación de trabajo. Por ejemplo, el trabajador no estaría protegido por la normativa actual frente a la existencia de listas negras que impiden la contratación de ciertos dirigentes sindicales en diversos sectores. Nuevamente, queda la opción del amparo, con la ya mencionada limitación de la inexistencia de etapa probatoria.

En segundo lugar, durante la ejecución del contrato de trabajo también se pueden dar afectaciones de derechos fundamentales, comúnmente encubiertas en descensos de categorías, traslados, retraso en pagos, etcétera. Las pocas protecciones que se han introducido en esta materia se han sumado por la vía del cese de la hostilidad. Así, según el artículo 30 de la LPCL, un trabajador se puede sentir hostilizado si es presa de un acto discriminatorio, si no se observan normas mínimas de seguridad e higiene laboral, o si se afecta de manera genérica la dignidad del trabajador. Me llama la atención que se incorpore a los supuestos de hostilidad típicos, tales como traslados, reducciones de categoría o de salarios impuestos de modo arbitrario, afectaciones de derechos fundamentales cuya naturaleza es distinta a un simple acto de hostilidad.

Creo que esta crítica es fundada por cuanto según el artículo 35 de la LPCL, el trabajador que se considere hostilizado solo puede reclamar o bien la cesación de la hostilidad y el pago de una multa por parte del empleador o bien la terminación de su contrato de trabajo. Como se ve, esta vía procesal del cese de hostilidad no repone las cosas al estado anterior, ni tampoco introduce mecanismos de facilitación probatoria. Con ello me refiero a la necesidad de mecanismos indiciarios como el impedimento de cualquier acto de perjuicio a los dirigentes sindicales durante el período de su representación o a las madres gestantes durante el período de su embarazo. Esto permitiría mayores garantías procesales como se permite en el despido nulo. Dudo mucho que un 
juez laboral, saliéndose del marco del artículo 35 de la LPCL, ordene la reposición de las cosas al estado anterior de la violación?.

Nuevamente, ante la insuficiencia de la vía procesal ordinaria, quedará expedita la vía del amparo con el ya apuntado problema de la inexistencia de etapa probatoria.

\section{LOS PROCESOS ORDINARIOS LABORALES EN LA NUEVA LEY PROCESAL DEL TRABAJO}

Frente a esta inadecuada legislación laboral de cara a la protección de los derechos fundamentales, la Nueva Ley Procesal del Trabajo tuvo la ocasión de revertir esta situación. No obstante, por lo que podemos observar, parece que la tutela de los derechos fundamentales en sede laboral no fue un objetivo prioritario del legislador procesal. Antes al contrario, el tratamiento de esta materia es dispersa y heterogénea.

$\mathrm{Al}$ no existir un proceso especial de tutela de derechos fundamentales, la tutela de aquellos o bien debe tramitarse vía proceso ordinario laboral o bien por el proceso abreviado.

Es difícil hacer una ponderación acerca de cuál de estos procesos se corresponde mejor con la naturaleza de tutela urgente de los derechos fundamentales del trabajador, sin embargo, me parece que el proceso abreviado es el que reconoce mejor el rasgo de «celeridad acentuada».

En un intento por establecer coordenadas comparativas, vamos a decir que el proceso ordinario es bastante más lento que el proceso abreviado, debido a dos cuestiones principales. Primero, el proceso ordinario implica una etapa conciliatoria que no tiene el proceso abreviado. En efecto, las audiencias del proceso ordinario son dos: la de conciliación y la de juzgamiento. Habría que aclarar, además, que cuando las partes no asisten a la conciliación pueden pedir que se reprograme la fecha de la conciliación. De este modo, si solo el proceso abreviado cuenta con una audiencia única no hay duda de que este reproduce de manera más exacta el principio de celeridad acentuada en materia de protección de derechos fundamentales. Además, resulta inocuo introducir una etapa de conciliación en un proceso de lesión de derechos fundamentales, puesto que estos son indisponibles e inconciliables.

Segundo, los plazos del proceso abreviado son en general menores que los del proceso ordinario. No solo porque no se podrá extender la conciliación más allá de una audiencia, sino porque la contestación de

9 También critican la eficacia protectora del cese de hostilidad, ZAVALA COSTA, Jaime \& VíLCHEZ GARCÉS, Lidia. «El nuevo reto procesal de protección de la libertad sindical en el marco de la Nueva Ley Procesal del Trabajo: ¿Hacia un retorno a la vía laboral?». En Doctrina y Análisis sobre la Nueva Ley Procesal del Trabajo. Lima: Academia de la Magistratura del Perú, p. 222. 
la demanda se hará a los diez días de notificada la demanda. Esto permite que la parte demandante llegue a la audiencia única conociendo los argumentos del demandado. Asimismo, la realización de otra audiencia de juzgamiento será muy excepcional, cuestión que no parece tan clara desde la perspectiva del proceso ordinario.

Es obvio que la comparación formulada la hemos hecho a partir de un rasgo muy puntual: la celeridad acentuada que requieren los procesos de tutela de derechos fundamentales. En los demás rasgos, no hay prácticamente diferencias de grado. Por ejemplo, la prioridad para los derechos fundamentales no opera ni en un proceso ordinario ni en un proceso abreviado, las medidas cautelares prescritas en la ley se aplican indistintamente para uno o para otro, etcétera.

Pero, si claramente el proceso abreviado se adapta mejor a las necesidades de la tutela de derechos fundamentales, entonces, ipor qué en ciertos casos la protección de estos derechos se ha encargado a la vía ordinaria? Este es un tema sin respuesta, aunque como veremos a continuación no parece tratarse de un lapsus legislativo. A continuación revisaremos las competencias de cada tipo de proceso en la Nueva Ley Procesal del Trabajo.

\section{COMPETENCIA DEL PROCESO ABREVIADO LABORAL EN} MATERIADELESIONESDEDERECHOS F UNDAMENTALES

Dado que el procedimiento abreviado laboral es aquel que respeta el principio de celeridad acentuada y, por ello, el que mejor corresponde a la tutela de derechos fundamentales, pasaremos a enunciar qué pretensiones se pueden ventilar en este procedimiento de conformidad con la Nueva Ley Procesal del Trabajo.

\section{V.1. Las pretensiones relativas a la vulneración de la libertad sindical}

Toda vulneración de los derechos de sindicación, negociación colectiva y huelga serán tramitados en el proceso abreviado (artículo 2.3 de la Nueva Ley Procesal del Trabajo). No importa el momento de la lesión, sea el acceso, la ejecución o la extinción de la relación laboral, pues el juez laboral, a través del procedimiento abreviado, es el encargado de proteger la libertad sindical.

Aunque a primera vista, este aporte legislativo sea un avance importante en esta materia, me temo que solo se trata de la apertura de una vía procesal específica. Hubiera sido muy interesante que la introducción de la nueva vía procesal venga acompañada de normas sustantivas que establezcan reglas de facilitación probatoria (por ejemplo, presunciones 
legales como «la protección de los despidos antisindicales abarca el tiempo de la representación del dirigente y hasta 90 días posteriores al término de su representación», así como las que juegan en el despido nulo) y otras que maticen la nulidad de todo acto lesivo de la libertad sindical en función de su naturaleza. Es verdad que abrir la vía procesal ya es un avance, pero también es evidente que si no hay normas en este sentido será muy difícil probar la violación alegada o que el juez reponga las cosas al estado anterior de la vulneración de la libertad sindical.

Quizá alguien podrá decir que la nulidad de todo acto lesivo de la libertad sindical se deriva de la jurisprudencia del TC en materia de amparo. Sin embargo, no se debe olvidar que la mayoría de sentencias del TC, por no decir su totalidad, ha tratado de lesiones a la libertad sindical durante la ejecución del contrato (traslados, reducciones de categoría, etcétera) o durante su extinción. ¿Cómo se ha de reparar una lesión en el acceso de la relación laboral? ¿Basta con declarar la nulidad del acto de contratación?, obviamente, no. Es por eso que se requieren reglas específicas con el fin de solucionar todos estos problemas ${ }^{10}$.

\section{V.2. De la reposición cuando esta se plantee como pretensión principal única}

Aquí, el artículo 2.2 de la Nueva Ley Procesal del Trabajo tiene una frase muy ambigua que puede generar muchos problemas de interpretación. En efecto, este artículo señala que se recurre al procedimiento abreviado cuando se demanda la reposición como pretensión principal única.

Es evidente que este inciso se aplica solo a casos de despido. Y no queda ninguna duda de que se aplicará a los despidos violatorios de derechos constitucionales que no tienen vía procesal específica en sede labora ${ }^{11}$. De este modo, ingresan las pretensiones de despido incausado, fraudulento y todos aquellos despidos que violen derechos excluidos del artículo 29 de la LPCL (exclusiones del despido nulo).

Se ha debatido académicamente sobre la inclusión del despido nulo laboral en este procedimiento, así como sobre su exclusión del mismo. El mayor argumento utilizado es que la pretensión procesal que subyace al despido nulo es la nulidad del despido. No así la reposición, pues la reposición sería solo un efecto de la nulidad. Esta postura ubicaría al

10 Quizá la eficacia de la protección de derechos fundamentales no sea solo un problema logístico y técnico de aplicación de la Nueva Ley Procesal del Trabajo, como afirman Zavala y Vílchez (ZAVALA COSTA, Jaime \& Lidia VílCHEZ GARCÉS. Ob. cit. pp. 229-230), sino también un problema de desarrollo sustantivo legislativo en temas relevantes como prueba y reparación de la libertad sindical vulnerada.

11 Sobre este tema, ver también el excelente trabajo de MURILLO FLORES, Luis Fernando. «La pretensión de reposición en la Nueva Ley Procesal del Trabajo (Ley N²9497)». Soluciones Laborales, 39 (2011), pp. 80-88.

LA TUTELA

LABORAL DE LOS

DERECHOS

FUNDAMENTALES

DEL TRABAJADOR.

UNA ASIGNATURA

PENDIENTE EN

TIEMPOS DE

REFORMA

THE LABOR

GUARDIANSHIP

OF WORKER'S

FUNDAMENTAL

RIGHTS:

A PENDING

SUBJECT IN TIMES

OF REFORM 
despido nulo en la vía ordinaria laboral, con todos los defectos que esta decisión conllevaría ${ }^{12}$.

Considero que esta interpretación literal del precepto es equivocada por las siguientes razones: en primer lugar, resulta irracional que el legislador procesal haya optado por dividir los casos de despido lesivo de derechos fundamentales en dos vías procesales distintas. Es más, ni siquiera todos los casos del artículo 29 de la LPCL irían al procedimiento ordinario, ya que los relativos a la libertad sindical pasarían al procedimiento abreviado en función del artículo 2.3 de la Nueva Ley Procesal del Trabajo.

En segundo lugar, sabiendo que el procedimiento abreviado calza mejor que el procedimiento ordinario con la naturaleza de los derechos fundamentales, sobre todo por el respeto a la celeridad acentuada, el desplazar el despido nulo a este último procedimiento constituye un atentado contra la tutela jurisdiccional efectiva (artículo 139.3 de la Constitución).

En tercer lugar, el despido nulo no encaja en un procedimiento ordinario laboral en la medida que este cuenta con una etapa de conciliación de intereses. iSe puede conciliar sobre la base de un derecho fundamental? Desde mi punto de vista, no es posible porque el mismo artículo 34 (tercer párrafo) señala que el demandante puede optar por la indemnización solo en la ejecución de sentencia. De esta manera, el juez que acepte una conciliación en un proceso de despido nulo estaría cometiendo un acto contrario a la ley imperativa y expresa. Entonces, si no se puede conciliar en este supuesto, ipor qué razón el despido nulo será tramitado en el procedimiento ordinario laboral? La etapa conciliatoria constituiría una dilación irrazonable.

En conclusión, el artículo 2.2 de la Nueva Ley Procesal del Trabajo abre las puertas en el procedimiento abreviado a todas las lesiones de derechos fundamentales producidas mediante el despido, incluido el despido nulo según lo dispuesto por el artículo 29 de la LPCL.

\section{V.3. Afectaciones al derecho de remuneración cuando el monto de la pretensión sea inferior a cincuenta unidades de referencia procesal (URP)}

Pareciera que el derecho a la remuneración no es un derecho fundamental o que ningún acto puede lesionarlo, debido a que el legislador procesal divide las competencias del procedimiento ordinario y del procedimiento abreviado solo en función del monto demandado. 
Por ejemplo, si a un trabajador no se le paga su remuneración mínima vital (RMV), entonces se está lesionando el derecho constitucional a la remuneración mínima. Nada tiene que ver en esta calificación que el monto demandado pase las cincuenta URP o no. Cualquier violación de la RMV debe ser tramitada como una lesión a un derecho fundamental, al margen del monto.

Este es un caso más donde es patente que el legislador procesal no tuvo en mente una posible violación del derecho a la remuneración, sino simplemente se visualizó la misma como un problema de cálculo. Creo que igual error cometió el TC en la sentencia Baylón Flores cuando señala con rotundidad que «el pago de remuneraciones y beneficios económicos» debe tramitarse en la vía ordinaria laboral. Tampoco el TC pudo advertir que el derecho a la remuneración es un derecho fundamental del trabajador y que puede ser lesionado ${ }^{13}$.

\section{COMPETENCIA DEL PROCESO ORDINARIO LABORAL EN MATERIA DE LESIONES DE DERECHOS FUNDAMENTALES}

De entrada, por lo dicho en páginas anteriores, el proceso ordinario laboral no es ni puede ser aceptado como vía de protección de derechos fundamentales. No obstante ello, paradójicamente el legislador procesal ha incluido en este tipo de procedimiento algunas lesiones de derechos fundamentales.

\section{VI.1. Los actos de discriminación en el acceso, ejecución y extinción de la relación de trabajo}

El artículo 2.1.c señala que los actos de discriminación en el acceso, ejecución y extinción de la relación de trabajo son tramitados en procedimiento ordinario. Llama poderosamente la atención qué es lo que tiene de diferente un acto violatorio de la libertad sindical de un acto violatorio del mandato de no discriminación. Simplemente, el adjudicar ambos tipos de violación de derechos fundamentales a procedimientos diferentes revela un error sistemático garrafal.

No creo que sea el único, por lo demás. El legislador menciona la generalidad de actos discriminatorios sabiendo que las discriminaciones producidas al momento de la terminación de la relación laboral son tramitadas vía despido nulo. Es una regulación caótica y contradictoria.

Finalmente, el juez ordinario laboral que se enfrente a una demanda donde se denuncia discriminación convocará a la audiencia de 
conciliación sin ningún sentido. Como ya se dijo, los derechos fundamentales de los trabajadores son indisponibles e irrenunciables. Quizá dentro de algún tiempo, la jurisprudencia subsane este error garrafal del legislador procesal y reconduzca estas lesiones por la vía del procedimiento abreviado.

\section{VI.2. El cese de los actos de hostilidad del empleador}

El Tribunal Constitucional peruano, en el considerando 18 del caso Baylón Flores, afirma sin ningún desparpajo que los amparos que se refieran a cese de hostilidad (artículo 30 de la LPCL), que por mandato de la ley son competencia de los jueces de trabajo, serán declarados improcedentes en la vía del amparo.

De esta manera, el TC afirma implícitamente que el cese de hostilidad es una vía específica e igualmente satisfactoria que el amparo y tramitada en vía ordinaria. Quizá el TC se guía por el hecho de que el artículo 30 de la LPCL reconoce como hostilidad a algunas violaciones de derechos fundamentales (no discriminación y dignidad). Sin embargo, hay dos razones de peso que cuestionan la decisión de nuestro TC. Primero, los supuestos de hostilidad son taxativos, de modo que muchos derechos fundamentales quedan excluidos. Segundo, la vía del cese de hostilidad está pensada para actos de hostilidad sin trascendencia constitucional (por ejemplo, traslados, reducciones de categoría, incumplimientos de pago de remuneración, etcétera) que conlleven el simple cese de la hostilidad (artículo 35.a de la LPCL), pero no puede utilizarse en los casos en que se debe declarar la nulidad de los actos lesivos de derechos fundamentales. La nulidad de la hostilidad no existe como un imperativo reparador en la LPCL.

En consecuencia, la vía del procedimiento ordinario laboral no calza con la eficacia reparadora del cese de hostilidad, pero tampoco podríamos afirmar que las violaciones de derechos fundamentales en la ejecución del contrato serían tramitadas en el procedimiento abreviado. Creo que inevitablemente quedarían en el proceso ordinario, con las complicaciones que ello supone, salvo para el caso de las violaciones de la libertad sindical. Ello, sin duda, devaluaría el mecanismo protector de la Nueva Ley Procesal del Trabajo.

\section{VII.EN ESTAS CIRCUNSTANCIAS, ¿ES IMPROCEDENTE LA ACCIÓN DE AMPARO?}

El Código Procesal Constitucional en su artículo 5, inciso 2 señala que «no proceden los procesos constitucionales cuando: [...] 2) Existan vías procedimentales específicas, igualmente satisfactorias, para la protección del derecho constitucional amenazado o vulnerado, salvo cuando se 
trate del proceso de hábeas corpus». Es decir, si existe un procedimiento ordinario específico para la tutela de derechos fundamentales y si este procedimiento otorga iguales garantías para los mismos, entonces no se podrá recurrir a la acción de amparo.

Sinceramente, la Nueva Ley Procesal del Trabajo no ha creado un proceso ad hoc para la protección de derechos fundamentales y ha optado por un sistema disperso y caótico para la protección de los mismos. Además, ya hemos visto que el proceso ordinario laboral no respeta el rasgo básico de «celeridad acentuada», con lo cual hay una evidente violación al derecho de tutela judicial efectiva que exige mecanismos reparadores eficaces y urgentes. Sin embargo, aunque el proceso abreviado sí lo hace, tampoco asegura una garantía similar a la de la acción de amparo respecto de los derechos fundamentales. Por ejemplo, no se establece la característica de prioridad que debe asumir un proceso donde se discuta la posible lesión de un derecho fundamental.

El otro tema que devalúa la utilidad de los procedimientos ordinario y abreviado es la ambigüedad que supuestamente tendría el juez laboral para reponer las cosas al estado anterior a la violación del derecho. Quizá con la única excepción del despido nulo, en la mayoría de las vías tramitadas por procedimiento abreviado es discutible si la nulidad se puede imponer sin base legal específica. En otros casos, como en el acceso al trabajo, el legislador no repara en que la nulidad de la contratación laboral no remedia la alegada violación del derecho fundamental.

De este modo, parece que el único camino es recurrir de vuelta a la acción de amparo, con lo cual la Nueva Ley Procesal del Trabajo habrá perdido una gran oportunidad para dotar al juez laboral de la posibilidad de evaluar con profundidad los atentados contra los derechos fundamentales del trabajador. Sin embargo, de lo que no se ha percatado el legislador procesal es que la acción de amparo no tiene etapa probatoria y el TC cada vez restringe más y más el acceso de estos temas por la vía constitucional del amparo ${ }^{14}$. Podríamos decir que la incapacidad del proceso laboral será subsanada por el TC, aunque esta vez todo parece indicar que no lo será ${ }^{15}$.

14 Paúl Paredes ha intentado explicar el motivo de esta omisión señalando que «crear un proceso ad hoc de tutela de derechos fundamentales en vía laboral hubiera significado la improcedencia del amparo» («La Nueva Ley Procesal del Trabajo y la Acción de Amparo». En Doctrina y Análisis sobre la Nueva Ley Procesal del Trabajo. Lima: Academia de la Magistratura del Perú, 2010, p. 124). Creo que la visión es equivocada, ya que el TC, con o sin proceso ad hoc, ha optado por la improcedencia del amparo en la mayoría de casos donde se discuten derechos fundamentales laborales. Aquí el problema no es solo jurídico, sino también político jurisdiccional. En consecuencia, si este fue el motivo para rechazar un procedimiento específico y es previsible que el TC mantendrá su posición, entonces queda claro que los únicos perjudicados serán los trabajadores.

15 Como ya lo señaló el mismo TC (ver sentencia recaída en el expediente 206-2005-PA/TC, caso Baylón Flores), solo se podrán tramitar amparos «atendiendo a la urgencia del caso o a la demostración objetiva y fehaciente por parte del demandante de que la vía laboral ordinaria no es la idónea". Como se puede observar, son casos muy excepcionales y que requieren de una voluntad amplia de parte de los magistrados del TC. 
En suma, nos encontramos en medio de una vía ordinaria insuficiente y otra vía extraordinaria, la del amparo, también incapaz de asumir la pesada carga de una limitada ley procesal en esta materia. Seguiremos esperando un proceso especial de tutela de los derechos fundamentales para continuar el camino que hace unos años abrió el mismo TC en sus sentencias. 